\title{
A Measurement Method of Determining the Power Supply Parameters for the Optimal Operation of a Synchronous Motor
}

\author{
Henryk Banach \\ The Faculty of Electrical Engineering and Computer Science, Lublin University of Technology, ul. Nadbystrzycka 38 A, \\ 20-618 Lublin, Poland; h.banach@pollub.pl
}

\begin{abstract}
The article presents a measurement method for determining the power supply parameters for the optimal operation of a synchronous motor, i.e. operation with minimal losses in the entire load range. The measurement strategy is based on the search for the minimum sum of the power supplied to the excitation circuit and the stator circuit for the assumed load torque values. The process of searching for the minimum sum of power can be significantly shortened and simplified by using a network parameter meter. The research confirmed the usefulness of the proposed method for determining the optimal operation parameters of a synchronous motor. The tested motor was a machine with a cylindrical rotor, but the developed method will also be applicable to synchronous machines with salient pole rotors.
\end{abstract}

Keywords: Synchronous motor, measurement method, loss minimization, optimal operations, optimal power supply parameters.

\section{INTRODUCTION}

The issue of the operational minimization of power losses in electric motors has been the subject of research for many decades. The largest number of studies has been focused on induction motors, as their share in electric drives exceeds $90 \%$. More and more attention is paid to PMSM and MIPMSM synchronous permanent magnet motors, [1]-[7]. On the other hand, the interest in synchronous motors with electromagnetic excitation is declining. This may be due to the fact that such machines are most often built as medium and high power motors. So far, little work has been published on the minimization of power losses in these motors [8]-[11]. The lack of interest may also result from the fact that in the case of control enabling energy-saving operation, it is necessary to give up the valuable property of the motor, which is the ability to generate inductive reactive power by an overexcited machine. The entire difficulty of optimal control results from the necessity to select the appropriate value of the supply voltage and the appropriate value of the excitation current for a given load. For an induction motor, the development of control for optimal operation comes down to the selection of only one parameter, which is the supply voltage. In the case of a synchronous motor, the determination of optimal power supply parameters may be performed by laboratory measurements or by simulation calculations. In the course of laboratory tests, many tedious measurements should be made, linking the supply voltage, excitation current and load moment. This would be a difficult and time-consuming task. Therefore, it was necessary to develop an appropriate measurement strategy to simplify and reduce the number of measurements leading to the determination of the optimal power supply parameters.

The aim of the conducted research was:

- development of a measurement method allowing the determination of power supply parameters for optimal operation of a three-phase synchronous motor, which will allow for a significant reduction in the time allocated to measurements and their significant simplification by introducing a network parameter meter into the measurement system,

- demonstration that a synchronous motor powered by the optimal parameters determined with the use of the developed method operates with lower losses than when powered by rated parameters appropriate for a given frequency,

- testing the behavior of selected power supply parameters under optimal operating conditions.

Fulfillment of the assumed properties of the measurement method was achieved by introducing a network parameter meter into the measurement system. The inspiration was the earlier use of such a meter to determine the optimal operating parameters of a synchronous reluctance motor, which was a much easier task, because in this case only one optimal parameter was sought, which was the supply voltage [13].

\section{Electromagnetic tORQue, POWER LOSSES AND EFFICIENCY OF A SYNCHRONOUS MOTOR}

The electromagnetic moment $T_{e}$ in a synchronous motor with a cylindrical rotor is described by the following equation 


$$
T_{e}=\frac{m}{2 \pi n_{s}} \frac{U_{p h} U_{i}}{X_{d}} \sin v
$$

where: $m$ - number of phases, $n_{s}$ - synchronous speed, $U_{p h}$ phase supply voltage, $U_{i}$ - voltage induced in the stator winding, $X_{d}$ - synchronous reactance, $v$ - power angle.

In such a synchronous machine the electromagnetic moment is proportional to the supply voltage and the induced voltage generated by the excitation flux, the value of which depends on the excitation current. The selection of power supply parameters in the form of supply voltage and excitation current is important for the process of minimizing power losses in the machine.

In a synchronous motor we can distinguish losses independent of the load. These include mechanical losses $P_{m}$, i.e. losses due to friction in bearings and losses on ventilation. The next losses are the losses depending on the machine excitation current. These include losses in the machine core (iron losses) $P_{F e}$ related to the phenomenon of magnetization of the core and the resulting hysteresis losses and eddy current losses. The largest group of losses are the losses depending on the machine load. They arise as a result of the current flow through the stator windings $P_{w}$ and are determined according to the relationship

$$
P_{w}=3 I_{p h}^{2} R_{p h}
$$

where: $I_{p h}$ - phase current, $R_{p h}$ - resistance of one stator phase. Additional losses $P_{a}$, the value of which is most often estimated, are also dependent on the load [12].

$$
P_{a}=(0.002-0.005) P_{N}
$$

The power supplied to the synchronous motor $P_{\text {in }}$ consists of the power supplied to the stator circuit $P_{\text {ins }}$ given by the equation

$$
P_{i n s}=3 U_{p h} I_{p h} \cos \varphi
$$

and the power supplied to the excitation circuit $P_{\text {inf }}$ by:

$$
P_{\text {inf }}=U_{f} I_{f}
$$

where: $U_{f}$ - supply voltage of the excitation circuit, $I_{f}$ - excitation current.

The total power $P_{\text {in }}$ fed to the synchronous motor will be equal to

$$
P_{i n}=P_{i n s}+P_{i n f}
$$

while total losses will be equal to:

$$
P_{t}=P_{m}+P_{F e}+P_{w}+P_{a}
$$

In the case of the method applied, the efficiency was determined by the direct method according to the following dependence

$$
\eta=\frac{P}{P_{\text {in }}}
$$

where: $P$ - motor shaft power.

\section{DESCRIPTION OF THE METHOD}

It is best to start the measurements with the rated load $P_{N}$ occurring at the rated supply voltage $U_{p h N}$, the rated stator current $I_{S N}$, and the rated excitation current $I_{f N}$. For example, for the assumed load we assume changes in the excitation current in the range $\left(I_{\text {fmin }}-I_{\text {fmax }}\right)$ by the value $\Delta I_{f}=0.25 \mathrm{~A}$, Fig.1.

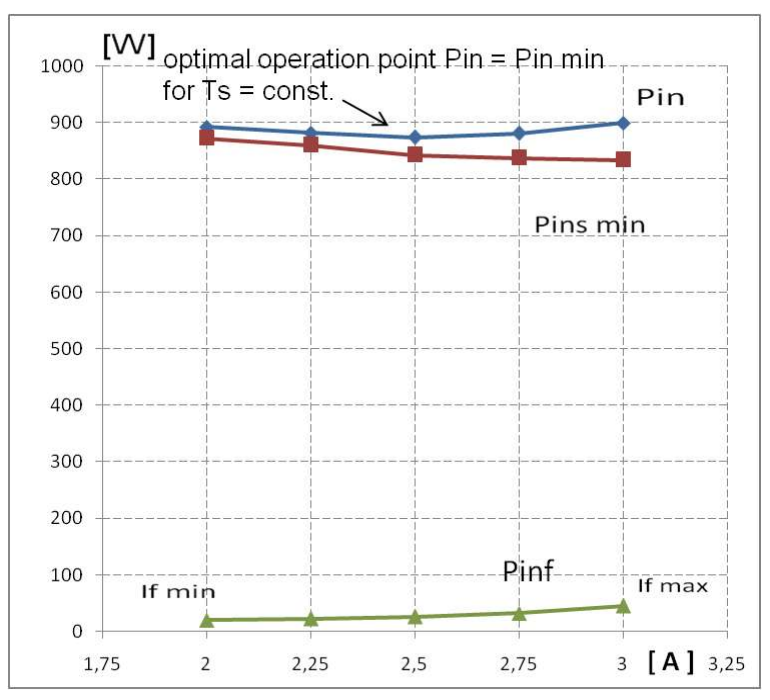

Fig.1. Measurements of individual powers $P_{\text {ins } \min }$ and $P_{\text {inf }}$ for the selected values of the excitation current of the synchronous motor and the adopted value of the load torque $T_{S}=$ const.

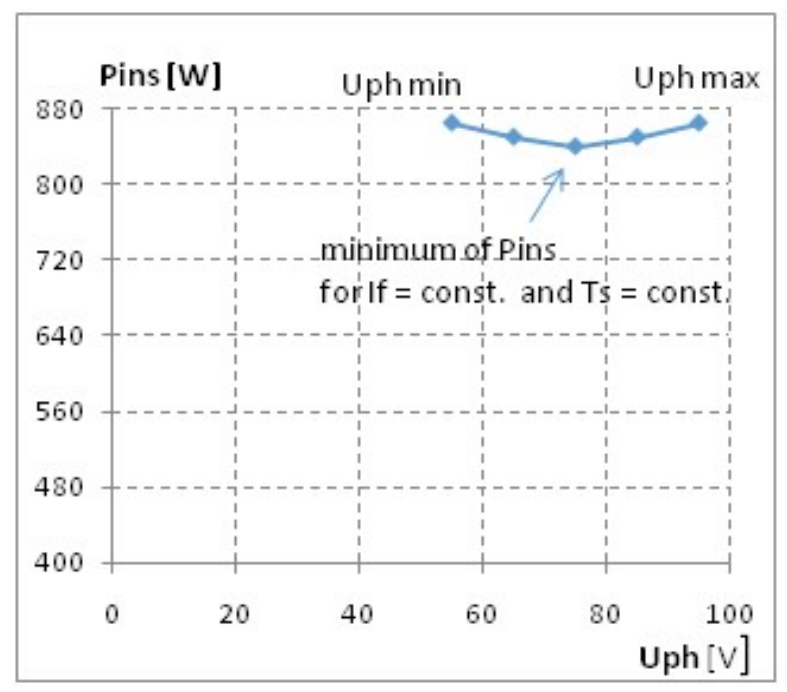

Fig.2. Searching for the minimum power $P_{i n s}$ by changing the value of the supply voltage from $U_{p h \text { max }}$ to $U_{p h \text { min }}$ for the adopted value of the excitation current $I_{f}$ and constant value of the load torque $T_{S}=$ const. 
For each set value of the excitation current, the value of the supply voltage is changed in the range $\left(U_{\text {phmax }} \div U_{\text {phmin }}\right.$ ) by means of an inductive voltage regulator so that the power $P_{\text {ins }}$ indicated by the network parameter meter reaches the minimum, Fig.2.

For the minimum power found, the sum of the power $P_{\text {in }}$ shown in Fig. 1. is calculated.

$$
P_{\text {in }}=P_{\text {ins } \min }+P_{\text {inf }}
$$

The search for the minimum power is carried out for the selected values of the excitation current in a specific range $\left(I_{f \min }-I_{f m a x}\right)$. For one of a series of selected excitation current values, the total power supplied to the $P_{\text {in }}$ motor will reach the minimum $P_{\text {in } \min }$ value, which will mean that the machine for these power parameters is at the optimal operating point. The voltage corresponding to this operating point will be the optimal voltage, while the excitation current will be the optimal current. Then we reduce the load on the machine and for the new value of the load torque we search the new range of excitation current changes in terms of the search for the minimum power delivered to the machine. In this way we find the next optimal work point. By carrying out such tests for several assumed load torque values, we can build the optimal control characteristics $U_{\text {ph opt }}=f\left(T_{S}\right)$ and $I_{\text {fopt }}=f\left(T_{S}\right)$ for the synchronous motor tested.

\section{MEASUREMENT OF OPTIMAL WORK PARAMETERS FOR FREQUENCIES OF 50, 40, 30, AND $20 \mathrm{HZ}$}

The object of the research was a synchronous motor with a cylindrical rotor based on a slip-ring induction motor. New stator and rotor windings were made and the air gap was enlarged in order to increase the overload capacity of the motor. The nominal parameters of the machine are shown below:

$$
\begin{aligned}
& P_{N}=1.5 \mathrm{~kW} \\
& U_{N}=200 \mathrm{~V} \\
& I_{S N}=5.5 \mathrm{~A} \\
& I_{f N}=4.0 \mathrm{~A} \\
& \cos \varphi_{N}=0.9 \\
& n_{s}=1500 \mathrm{rpm} . \\
& T_{N}=9.55 \mathrm{Nm} \\
& R_{p h s}=0.88 \Omega \\
& R_{f}=5.01 \Omega \text { (equivalent excitation circuit resistance) }
\end{aligned}
$$

The stator of the tested synchronous motor SS was supplied from a three-phase network through an inductive voltage regulator RI, which enabled the change of supply voltage amplitude, Fig.3.

Measurements of averaged values of supply voltage, phase current, power factor and active power consumed from the network were made by the N10 network parameter meter. The excitation circuit was powered from the $6 \mathrm{D}$ rectifier, and the excitation current value was regulated by an inductive voltage regulator supplied from a three-phase network. The power supplied to the excitation circuit of the motor was measured with a wattmeter $\mathrm{W}$.
The load of the synchronous motor was measured with a dynamometer $\mathrm{H}$, which was a separately-excited $\mathrm{DC}$ generator operating at rated excitation current with the following parameters:

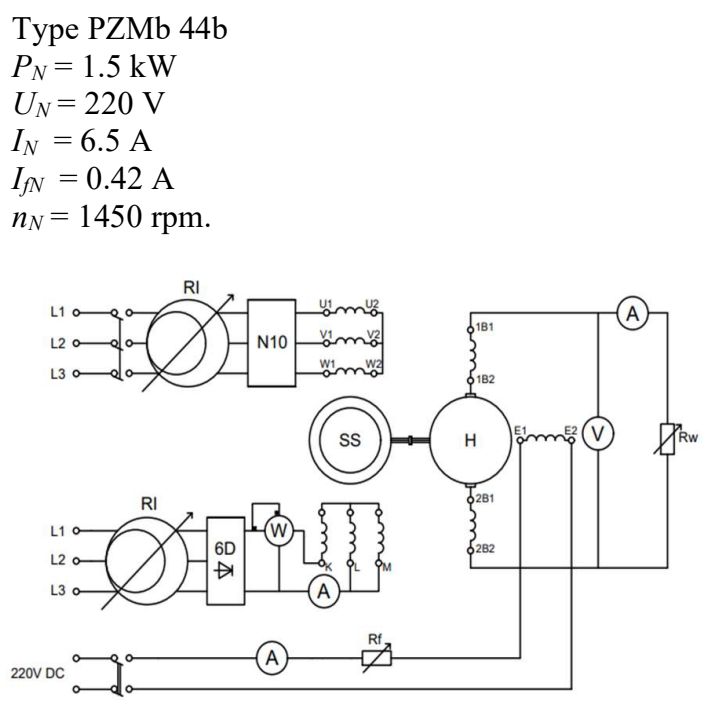

Fig.3. Scheme of the measuring system to determine the optimal parameter power supply for a frequency of $50 \mathrm{~Hz}$.

The load on the dynamometer was the resistor $\mathrm{R}_{\mathrm{W}}$ with adjustable resistance values.

Measurements of the optimal power supply parameters for lower frequencies of $f_{s}=40,30$, and $20 \mathrm{~Hz}$ were carried out with the use of a synchronous generator driven by an induction slip-ring motor powered by a frequency converter.

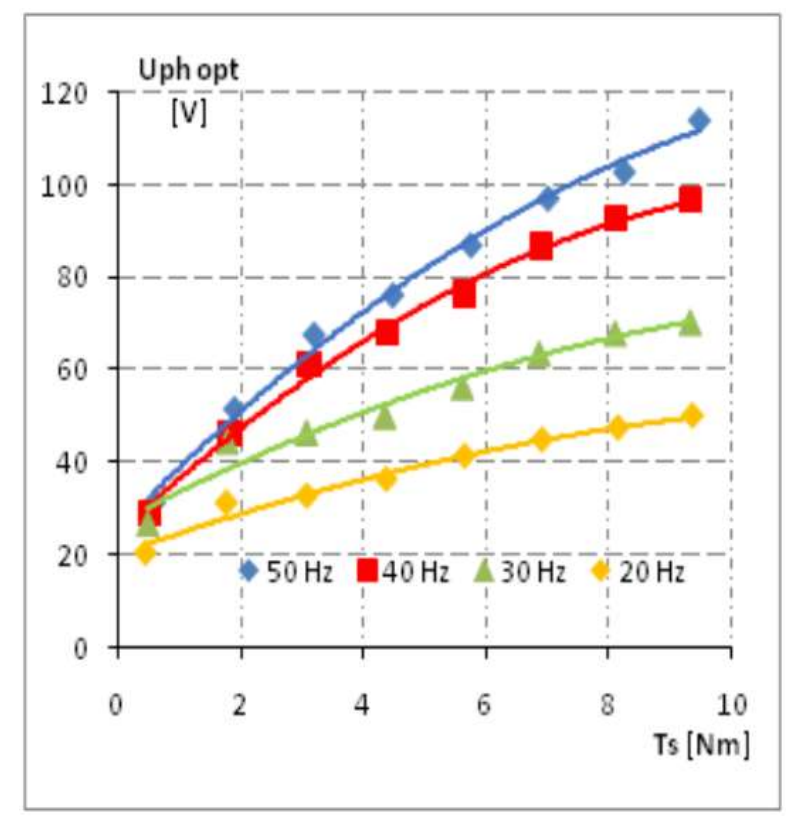

Fig.4. Characteristics of the optimal phase voltage $U_{p h}$ opt as a function of the load torque $T_{S}$ 
The performed measurements allowed for the development of the characteristics of the optimal power supply parameters $U_{\text {ph opt }}$ and $I_{\text {fopt }}$ as a function of the torque $T_{S}$ on the machine shaft for selected frequencies, Fig.4. and Fig.5.

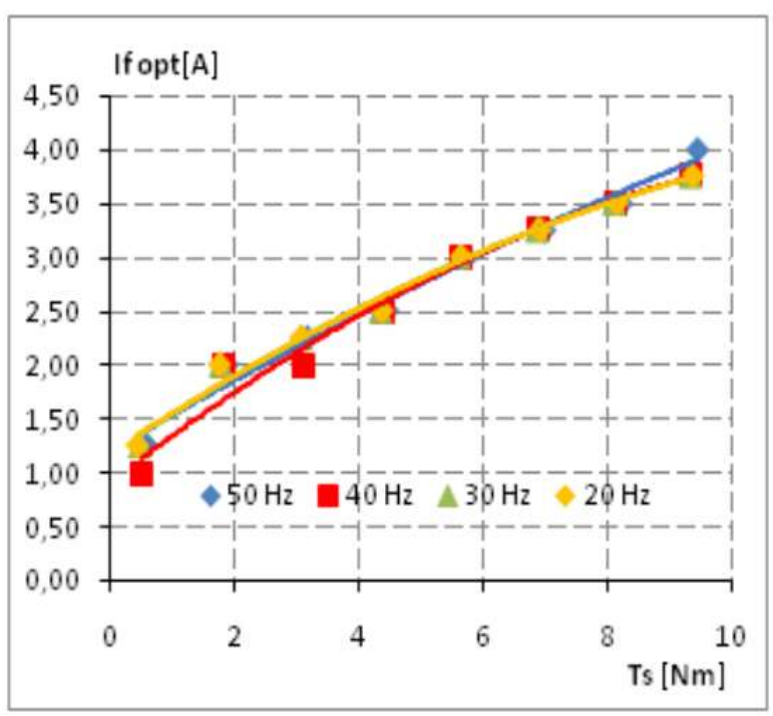

Fig.5. Characteristics of the optimal excitation current $I_{f}$ opt as a function of load torque $T S$.

It was also examined how the power factor $\cos \varphi_{\text {opt }}$ changes under optimal operating conditions. Fig.6. shows the values of the power factor depending on the load torque $T_{S}$ for all selected frequencies.

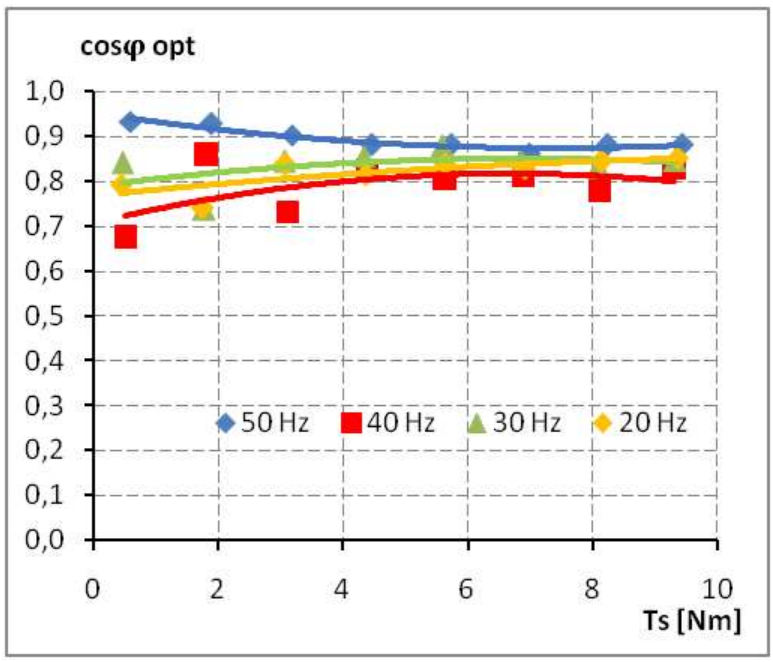

Fig.6. Characteristics of the optimal power factor $\cos \varphi_{\text {opt. }}$.

It turns out that the power factor values do not change much with increasing load and can be considered approximately constant for a given frequency. The motor then works with a slight underexcitation.

In order to present the benefits resulting from the optimal operation of the tested synchronous motor, Fig.7. shows the total power losses in the machine for the frequency of $50 \mathrm{~Hz}$ with the supply with the rated voltage and excitation current and the supply with optimal parameters.

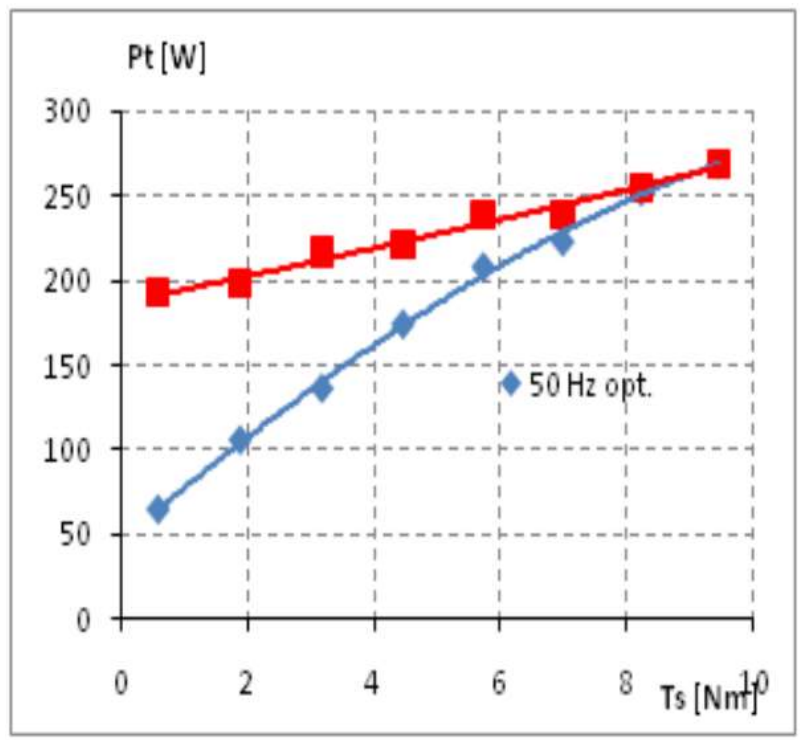

Fig.7. Total power loss for optimal operation (blue line) and for operation with rated voltage and rated field current (red line); $f_{S}=50 \mathrm{~Hz}$.

Fig.8. compares the machine efficiency in the conditions of optimal operation $\eta_{\text {opt }}$ and operation at the rated voltage and the rated excitation current.

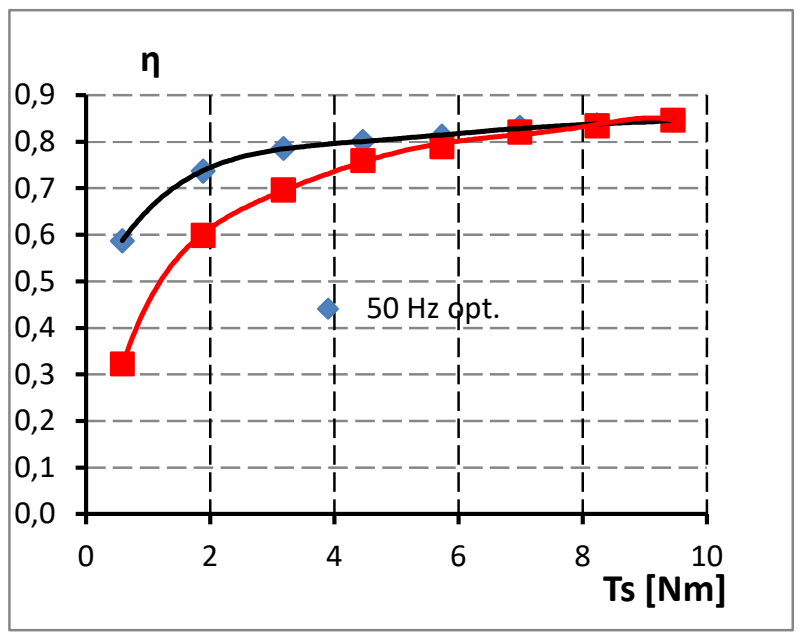

Fig.8. Efficiency characteristics for optimal operation (blue line) and for operation with rated voltage and rated field current (red line); $f_{S}=50 \mathrm{~Hz}$.

The total power losses and efficiency were also calculated for the frequency $f_{S}=30 \mathrm{~Hz}$ for both types of work. The calculation results are presented in the graphs, Fig.9. and Fig. 10. 


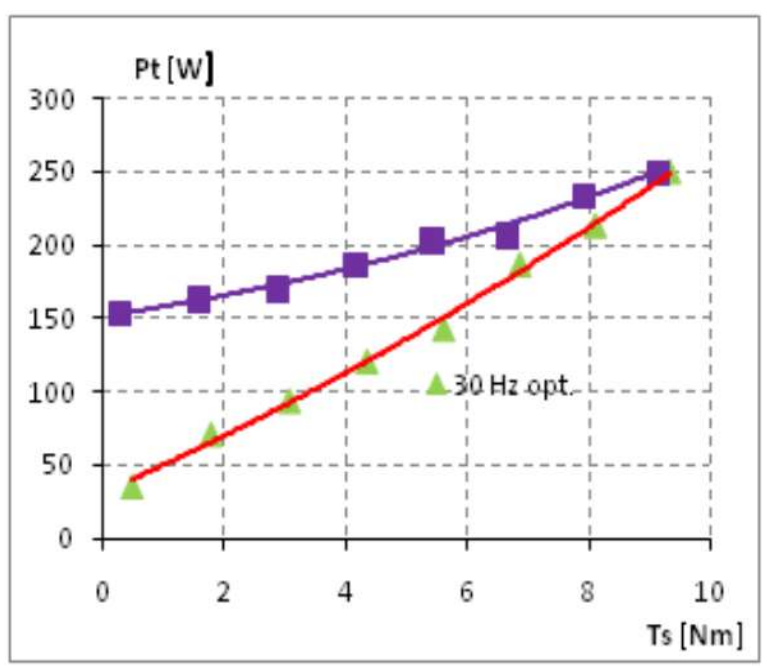

Fig.9. Total power loss for optimal operation (red line) and for operation with rated voltage and rated field current (blue line); $f_{S}=30 \mathrm{~Hz}$.

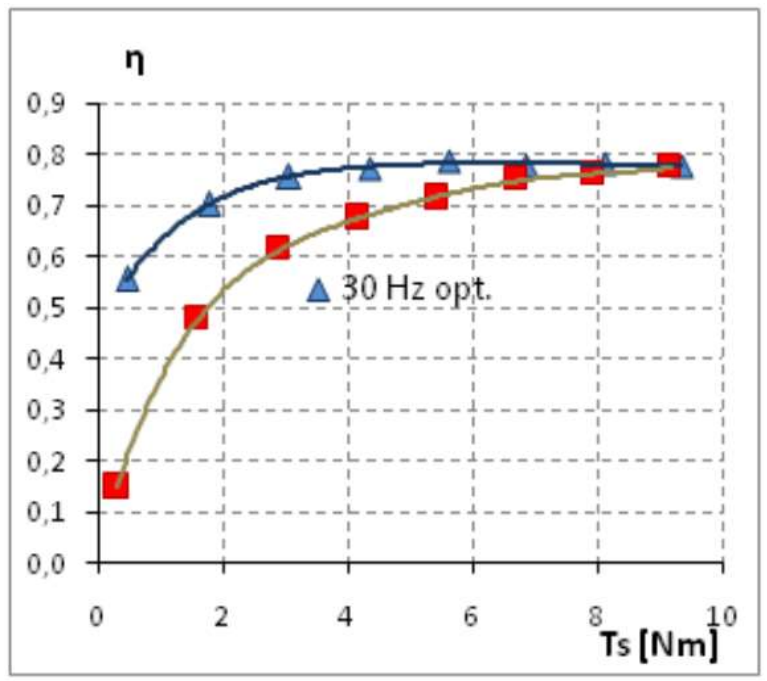

Fig.10. Efficiency curves for optimal operation (blue line) and for operation with rated voltage and rated field current (red line); $f_{S}=30 \mathrm{~Hz}$.

\section{CONCLUSIONS}

The conducted research leads to the following conclusions: 1. The presented method of determining optimal power supply parameters has been positively verified. The proposed strategy of conducting measurements with simultaneous tracking of the sum of the input power given to the stator circuit and the excitation circuit at the assumed load moment, i.e. constant power load on the shaft, allows for a relatively quick determination of the optimal parameter supply. This allows for a significant reduction in the number of measurements and the time needed to perform them. These effects were obtained by applying the described strategy with the use of a network parameter meter.
2. The described measuring method can be used for synchronous motors with cylindrical rotors and for rather low power salient pole motors. This limitation results from the rated data of the network parameter meter. In the event of their extension by the use of, for example, current transformers, measurements can be performed on motors with higher power.

3. The described measurement method can be used in didactic laboratories, e.g. laboratories for machines and electric drives, in order to show students the possibilities of optimal operation of a synchronous motor.

4. The optimal power supply parameters determined during the tests, i.e. supply voltage and excitation current for the adopted frequencies of $f_{s}=50,40,30,20 \mathrm{~Hz}$, can be used to control the synchronous motor in order to perform the optimal operation of the machine, i.e. work with minimum losses for each load value.

5 . The presented collective characteristics of optimal excitation currents indicate their small dispersion, which makes it possible to replace them with one averaged characteristic and use it to control the motor.

6 . The power factor for selected frequencies at optimal operation is lower than $\cos \varphi=1$ and can be considered approximately constant for a given frequency.

7. The presented diagrams of total losses for the rated parameters and for the optimal parameters, Fig.8., Fig.10. show the possibility of reducing losses, especially in the range of small loads. This significantly increases the efficiency of converting electrical power into mechanical power in the machine.

\section{REFRENCES}

[1] Guo, Q., Zhang, Ch., Li, L., Wang, M., Zhang, J., Wang, T. (2017). Loss optimization control of permanent-magnet synchronous machines drive system for electric vehicles. In 2017 IEEE Transportation Electrification Conference and Expo, Asia-Pacific (ITEC Asia-Pacific). IEEE.

[2] Jafari, S.H., Corzine, K.A., Huang, J. (2012). Efficiency optimization of a sensorless V/f control method for PMSM. In 3rd IEEE International Symposium on Sensorless Control for Electrical Drives (SLED 2012). IEEE.

[3] Chen, J., Zhang, Y., Hu, X., Zhang, Y. (2019). Improved efficiency of a PMSM drive with model predictive control. In 2019 IEEE International Symposium on Predictive Control of Electrical Drives and Power Electronics (PRECEDE). IEEE.

[4] Betí, L.T., Schäfer, U. (2014). Loss minimization algorithm of an IPMSM based on analytical expressions. In 2014 16th European Conference on Power Electronics and Applications. IEEE.

[5] Zhang, Ch., Guo, Q., Li, L., Wang, M., Wang, T. (2017). System efficiency improvement for electric vehicles adopting a permanent magnet synchronous motor direct drive system. Energies, 10 (12), 2030. 
[6] Mademlis, C., Kioskeridis, I., Margaris, N. (2004). Optimal efficiency control strategy for interior permanent-magnet synchronous motor drives. IEEE Transactions on Energy Conversion, 19 (4), 715-725.

[7] Chai, W., Lipo, A.T., Kwon, B. (2018). Design and optimization of a novel wound field synchronous machine for torque performance enhancement. Energies, 11 (8), 2111.

[8] Mademlis, C., Xypteras, J., Margaris, N. (1998). Loss minimization in wound-field cylindrical rotor synchronous motor drives. IEEE Transactions on Power Electronics, 13 (2), 288-296.

[9] Mademlis, C., Xypteras, J., Margaris, N. (1995). Loss minimization in synchronous motors. In 1995 Proceedings of the IEEE International Symposium on Industrial Electronics. IEEE, vol. 1, 297-302.

[10] Mademlis, C., Xypteras, J., Margaris, N. (2000). Magnetic and thermal performance of a synchronous motor under loss minimization control. IEEE Transactions on Energy Conversion, 15 (2), 135-142.
[11] Tang, J., Liu, Y. (2017). Comparison of copper loss minimization and field current minimization for Electrically Excited Synchronous Motor in mild hybrid drives. In 2017 19th European Conference on Power Electronics and Applications (EPE'17 ECCE Europe). IEEE.

[12] Dabrowski, M. (1988). Designing of Alternating Current Electrical Machines. Warsaw, Poland: WNT, 445. (in Polish)

[13] Banach, H. (2012). Minimalizacja strat mocy w trójfazowym synchronicznym silniku reluktancyjnym [Loss minimizing in a synchronous reluctance motor]. Zeszyty Problemowe-Maszyny Elektryczne, 94, 139143. (in Polish)
Received September 9, 2021

Accepted November 15, 2021 